\title{
Digital strategies for the valorisation of archival heritage
}

\author{
Roberta Spallone ${ }^{1}$, Giulia Bertola ${ }^{2}$, Francesca Ronco ${ }^{3}$ \\ ${ }_{1}^{1}$ Politecnico di Torino, Department of Architecture and Design, viale Mattioli 39, 10125, Torino, Italy \\ ${ }^{2}$ MODLab Arch, viale Mattioli 39, 10125, Torino, Italy \\ ${ }^{3}$ MODLab Design, Corso Settembrini 178, 10135 Torino, Italy
}

\begin{abstract}
$20^{\text {th }}$ century pre-digital architectural archives are a current topic of interest for scholars involved in historical studies as well as those studying conservation, valorisation and communication. These vast archival heritages could be enhanced by the methodologies, techniques and tools offered by the digital revolution. The present proposal demonstrates this potential through the application of structure from motion techniques to a physical scale model that represents the Turin Horse Racing designed by Carlo Mollino. Moreover, the paper presents a comparison of different software, methodologies and modelling tools and suggests a design for virtual and on-site communication strategies. These strategies fuel new interrelations of knowledge and ideas, through which an archive can become a place of convergence between the real and the virtual.
\end{abstract}

\section{Section: RESEARCH PAPER \\ Keywords: Architectural archives; structure from motion; 3D modelling; BIM modelling; augmented reality}

Citation: Roberta Spallone, Giulia Bertola, Francesca Ronco, Digital strategies for the valorisation of archival heritage, Acta IMEKO, vol. 10, no. 1, article 30, March 2021, identifier: IMEKO-ACTA-10 (2021)-01-30

Editor: Ioan Tudosa, University of Sannio, Italy

Received May 15, 2020; In final form November 6, 2020; Published March 2021

Copyright: This is an open-access article distributed under the terms of the Creative Commons Attribution 3.0 License, which permits unrestricted use, distribution, and reproduction in any medium, provided the original author and source are credited.

Corresponding author: Roberta Spallone, e-mail: roberta.spallone@polito.it

\section{INTRODUCTION}

The considerable amount of materials, predominantly design drawings, held in 20th century architectural archives are among the cultural heritage objects currently in need of conservation, valorisation and enhancement. Many international scholars are involved in the interpretation, fruition and sharing of archival materials with the aim of deepening the knowledge of contemporary masters and architectural movements. The safeguard of these archives depends largely on the discovery, analysis, knowledge and interpretation of their value as strongholds of cultural heritage.

Architectural archives were established relatively recently and given particular emphasis only from the end of the $1970 \mathrm{~s}$ onwards. Today, in the digital era, they are the object of new investigations.

In accordance with the opinion of Aleardi, we believe that the future of these archives lies in the creation of new forms of documentation for the architectural objects of which they are the narration. Aleardi further observes that, since archival documents frequently represent architectural objects that no longer exist, those that were imagined but never created or those that are distant, they therefore cannot convey the same power as direct, kinaesthetic experience [1].

Since the beginning of the 21 st century, the digitisation of the physical documents kept in the archives has become one of the best practices for preservation, as it reduces the direct manipulation of the sources, and communication, as it enables remote viewing of the original materials.

Digitisation has been performed with information and communications technology (ICT) tools, which have enabled the low cost scanning of documents and the sharing of sources to a wider public. Nevertheless, the simple digitisation of archival sources seems insufficient for transmitting the same degree of knowledge and meaning that is possible through on-site consultation, especially when it comes to design drawings and physical models.

In the case of drawings, the reduction in the scale and resolution of digital documents to enable consultation through screens smaller than the originals compromises the analysis and interpretation. To this is added the loss of the three-dimensional, material and tactile qualities of physical models. Moreover, the knowledge gained from the analysis of archival documents still needs to be interpreted, represented and communicated.

Contemporary architectural archives could be defined as being on the borderline of cultural heritage: in fact, they 
represent both documental and cultural heritage, so that they could be considered a hybrid of the archive and the museum [2].

Since the late 1970s, such institutions have been coordinated by international organisations including the International Confederation of Architectural Museums (ICAM) and the International Council on Archives (ICA). These organisations have created guidelines for architectural archives that focus on the preservation and sharing of knowledge, the management of which has been guaranteed thanks to specific international protocols regarding cataloguing, digitisation, preservation and fruition. Their first objective was the clear and univocal definition of an architectural document as every kind of documental material related to the history, theory and practice of architecture and related fields, independent from its support and physical characters, created or received by public or private authorities during their activity and gathered independently from its origin [3]. This definition establishes the great complexity of materials and interpretations related to architectural documents, including not only architectural drawings but also other kinds of materials (e.g. physical models, photographs, correspondence, structural calculations, costs and materials estimations, audio and video records) that could be differently interpreted by a potentially limitless public as historical proofs, technical documents or works of art. As Irace stated, the peculiarity of architectural archives consists in the purpose of their design, which almost always tends to project the dimensions of the document into the more heroic dimensions of a monument [4].

ICT enables methods of visualisation that are impossible in an ordinary encounter with a document, such as the integration of fragments or the $3 \mathrm{D}$ rendering of a drawing. In short, ICT tools exponentially heighten the capabilities of analysis, research, study and even communication. Contemporary research on architectural archives looks to multidisciplinary and crossdisciplinary approaches that could bring analysis, interpretation, communication and sharing into the digital era.

Design \& Cultural Heritage, Animated Archive, a fairly recent book edited by Fulvio Irace and Graziella Leyla Ciagà, is a collection of several proposals of this sort [5].

Among them, Leyla Ciagà's digital platform prototype, which aimed to dynamically relate existing artefacts with the archives that document their design development, stood out. The prototype set up by the scholar had two main aims in relation to two sets of users: first, sharing knowledge about 20th century architecture whose value and quality is often ignored in order to build support for preservation actions among a broader age demographic; and second, offering scholars a useful research tool in order to incentivise and inspire more in-depth studies performed directly on archival documents [6]. This work is a fundamental source of inspiration for our research.

In Section 2, we will present the case study and previous research.

In Section 3, we will analyse some case studies that provide background knowledge for the present work.

In Section 4, the structure from motion (SfM) methodology is applied to the physical model, and the object of this work is discussed.

Section 5 describes the technique for generating a digital model from a physical document.

Section 6 develops the scan-to-building information modelling (scan-to-BIM) process, highlighting the challenges encountered in this case study.
Section 7 underlines the potentialities of BIM for collecting and exchanging data and augmented reality to enhance the user's experience of the archive.

\section{ENHANCING ARCHIVAL ARCHITECTURAL HERITAGE OBJECTS THROUGH DIGITAL TOOLS}

Using the continuous innovations of digital modelling tools, a field of study aimed at the enhancement of archival architectural heritage objects is developing new and reconstructed interpretations of unbuilt projects or demolished buildings. Twentieth century archives from the pre-digital era contain many different materials - not only drawings, which, as mentioned, form the basis of this project's activities, but also technical reports, correspondence, pictures, photomontages, scale models and audio and video recordings. The value of the archives lies in the significance of these items, which provide proof of a phase in the design process that ended with the construction or remained on paper.

This is the case for Carlo Mollino's Archive, which since 1973 has been kept in the Archivi della Biblioteca Centrale di Architettura 'Roberto Gabetti', Politecnico di Torino, Fondo Carlo Mollino. Among the more than 130 architectural designs collected in the archive, only about twenty were fully realised, and many of those do not exist today due to thoughtless demolitions [7].

Several designs by Mollino were recently digitally reconstructed as part of a master's thesis undertaken in the School of Architecture at the Politecnico di Torino and supervised by Roberta Spallone and Sergio Pace. Another recent study created a unique collection of digital models of the most interesting and documented works, applying the latest low-cost technologies for user interaction and the integration of $3 \mathrm{D}$ modelling tools with publishing and online sharing systems. The prototyped platform, 'Digital Interactive MOllino' (DIMO), is experimental and replicable [8].

Frequently, Mollino paired his designs with physical scale models, which were documented in photographs and photomontages but not preserved. The models allowed him to visualise the physical appearance of the building within its environmental context. Among Mollino's designs, the Turin Horse Racing (Figure 1) was a youthful masterpiece that was built

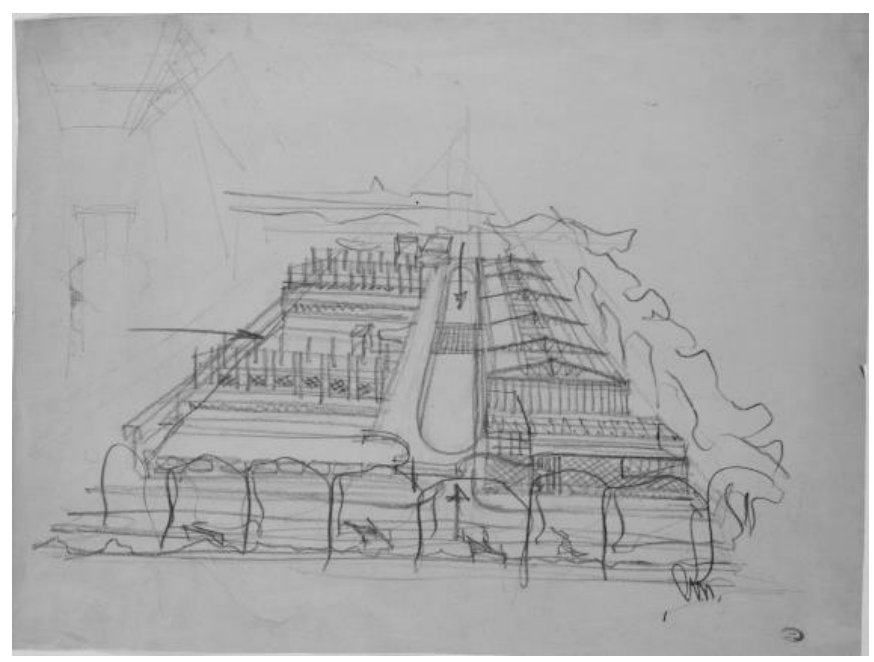

Figure 1. Mollino, sketch of Turin Horse Racing (Archivi della Biblioteca Centrale di Architettura 'Roberto Gabetti', in the following BCA, Politecnico di Torino. Fondo Carlo Mollino). 


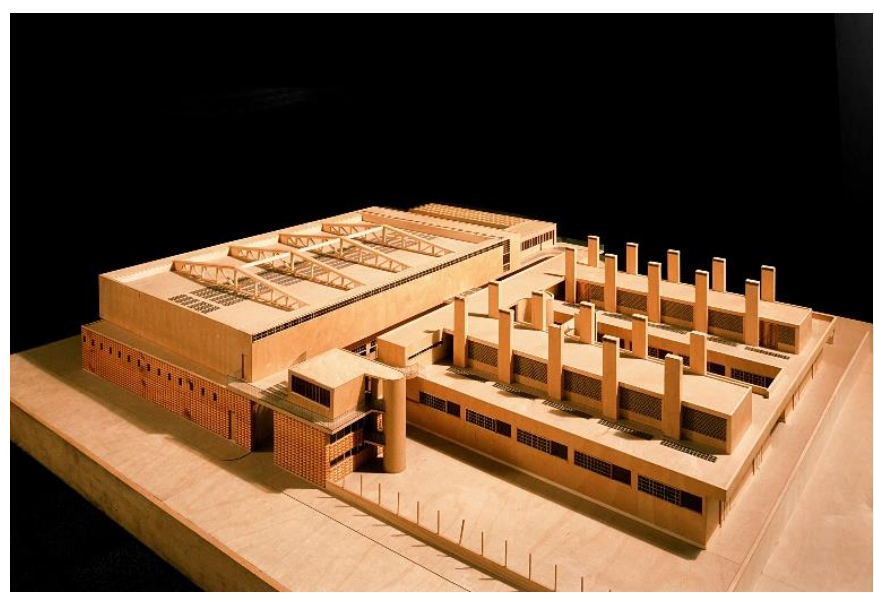

Figure 2. Wooden model of Turin Horse Racing (Archivi BCA, Politecnico di Torino. Fondo Carlo Mollino).

in 1937 and demolished in 1960 due to the urban transformation related to the celebration of the centenary of the Unification of Italy. It was later represented by a wooden scale model (Figure 2) that was presumably realised in the 1970 s or $80 \mathrm{~s}$ and is preserved in the Biblioteca Centrale di Architettura.

The availability of ontologically different representations of this project made it an interesting case for testing a new development of the DIMO prototyped platform. Indeed, in this particular case, it was possible to create a circular flow of knowledge between the physical archival heritage objects and the digital interpretations. The application of SfM to the wooden model enabled the creation of a 3D digital model that could be compared with a second digital model generated from the original drawings. Moreover, either the physical model or the drawings could provide the basis for marker-less experiences of augmented reality that link to other archival materials, point clouds and interpretative digital models. The archive could become a place for the exchange of knowledge and experiences. At the same time, the website could contain links to a selection of archival documents and interactive repositories, such as Sketchfab ${ }^{\circledR}$ or $3 \mathrm{DHOP} \AA$, enhancing the fruition of the archive and encouraging its use. The present phase of the work is focused on the application of SfM to the physical model and the creation of a 3D digital model of the Horse Racing.

\section{INTERPRETING AND SHARING ARCHITECTURAL HERITAGE: THE DIGITISATION OF PHYSICAL MODELS}

Scale models and maquettes evoke a high level of craftsmanship, crystalise ideas and anticipate the future. They aid the architect in 'knowing the beauty of a building, whose idea he just conceived, before even starting its construction' [9].

The wooden model in this case represents the threedimensional historic memory of a structure that has been demolished. Hence, it both looks backward and anticipates the future in the sense that it could be used for the crucial purpose of reconstruction, helping an architect bring the building back to life.

Therefore, the digitisation of physical models assumes even more importance when applied to entities that are about to be built or that do not exist anymore, as in the proposed case.

A combination of photogrammetric and laser scanning techniques are commonly used for surveys aiming at the production of integrated and accurate 3D representations. Both techniques are particularly useful for cultural heritage applications because they don't require direct contact with the object.

With the transition from analogical to digital culture, the transmission of data has radically changed both in principal and in method. Approaches to acquisition and analysis have transformed in kind [10].

The ability to digitise a wooden model, visualise it in a real setting and compare it with historical sources represents a new approach for the history of architecture and also for the process of the improvement of cultural heritage.

This was the case for a 2011 study of the Masieri Memoria building [11] in which photogrammetry and laser scanning were used to obtain models that were as precise as possible. When compared, the models were nearly overlapping.

Digitising techniques were also used to give viewers a sense of the realised building.

A model of a city was realised using municipal cartography (plans) and scans acquired by laser scanner (to capture heights). Using the camera match utility of 3D Max Studio ${ }^{\circledR}$, a procedure similar to a backward resection was applied using the city model as the context.

Another interesting case illustrating a combination of different techniques is the survey of a maquette by Antonio da Sangallo at the Basilica di San Pietro carried out in 2007 [12].

The survey was made using a laser scanner technique focusing on both the internal and the external views. The model in this case became a means for the evaluation of the overall design its spatiality, its geometry (which used control cross-sections to define the main generatrix and directrix) and its lighting characteristics. Thanks to the great accuracy of the model, it was possible to analyse its individual elements and compare them with the main classical treatises.

The maquette was also used to generate a virtual model through a process of reverse modelling. Using the model, a video was created from a human point of view to highlight the spatial characteristics of the building and point out some limitations of Sangallo's design, confirming some of Michelangelo's doubts about lighting.

This use of both virtual and reconstructed models introduces some interesting reflections about these different tools. The possibility of constructing a physical model (which, in some cases, is easier to construct and manipulate than a virtual model) in order to develop a digital model (which is more suitable for controlling dimensions and making drawings) therefore represents a particularly interesting track for the exploration of new approaches. This type of practice can benefit from numerous interactions between the analogue and digital models [13].

BIM technologies are also used to create digital models. A 2019 study used collection information modelling (CIM) to realise a 3D database of mobile heritage based on the collection of the Museo Egizio in Turin [14]. Although many of the objects explored in this study were smaller than a maquette, it is interesting to consider how museums can utilise achieved digital models for multiple purposes - for example, to monitor their collections and offer users (visitors) the possibility of exploring objects, even those that cannot be put on display due to a lack of space.

The efficiency and precision of digital instruments along with their interactivity, manipulability and suitability for multimedia applications are essential elements for a sustainable reproduction.

In all of the analysed studies, there was a need to strengthen the interaction and integration between different methods of 
representation from the most traditional to the most innovative (while maintaining a focus on accurate representation) and between the real structure, the model and the representation.

The analytic and interpretative approaches to modelling that were presented in case studies could be applied to the Turin Horse Racing maquette in order to enrich its significance as a cultural heritage item and its relevance as an object of scientific study.

\section{APPLYING STRUCTURE FROM MOTION TO PHYSICAL MODELS}

Today, digital and numeric models are gradually taking the place of maquettes, in particular the handmade wooden ones. A wooden model does exist in the case of the Turin Horse Racing, even though the building does not. Through modern 3D representations and surveying technologies (digital photogrammetry, in this case) we can insert this building into the current context. By applying translating processes to the realised maquette and its digitisation, it is possible to re-create reality in a specific context and engage in dialogue with a specific public.

Automated photogrammetry makes it possible to transform maquettes into digital models. This process is not yet common: typical applications concern whole buildings or small objects, not medium-sized things. Different sizes of objects and different accuracy requirements lead to the selection of different instruments and methods.

The common use of photogrammetry is not only due to the availability of technical tools and the fact that they are less expensive than the equivalent tools for laser scanning. Analysing this choice from a more conceptual point of view, photogrammetry and the subsequent photo modelling guarantee the construction of a model that directly transforms visible elements into the digital space. The obtained model thus provides a realistic representation of what we see. This technique is especially effective in situations in which the interpretation of geometry is not required. Photogrammetry can also be performed in order to obtain three-dimensional information.

Photo modelling is a highly realistic and efficient tool for describing the surface characteristics of objects and for creating $3 \mathrm{D}$ models that are verifiable and navigable from infinite points of view. This feature is interesting for the process of surveying maquettes. Even though maquettes are often characterised by a single material, photo modelling enables the restitution of their materiality and highlights small variations in the treatment of the surface.

Finally, thanks to its digital nature, photo modelling can make use of media techniques that connect images to stories by presenting a sequence of information that can be experienced as a narrative, while flanking the narrative with real data [15].

The wooden model of Turin Horse Racing used in the case study (Figure 3) has a 1:50 scale and dimensions of 176.5 (length) $\times 196.5$ (width) $\times 20 \mathrm{~cm}$ (height), so it can be considered neither big nor small. Therefore, as photogrammetry was used exclusively, it was important to take a sufficient number of photos from different points of view and with good illumination in order to obtain as precise a model as possible.

Following the rules of photogrammetry, the model was photographed in its entirety, making three turns around it at three different heights and taking photographs at each human step to allow a rich reconstruction using structure from motion (Figure 4).

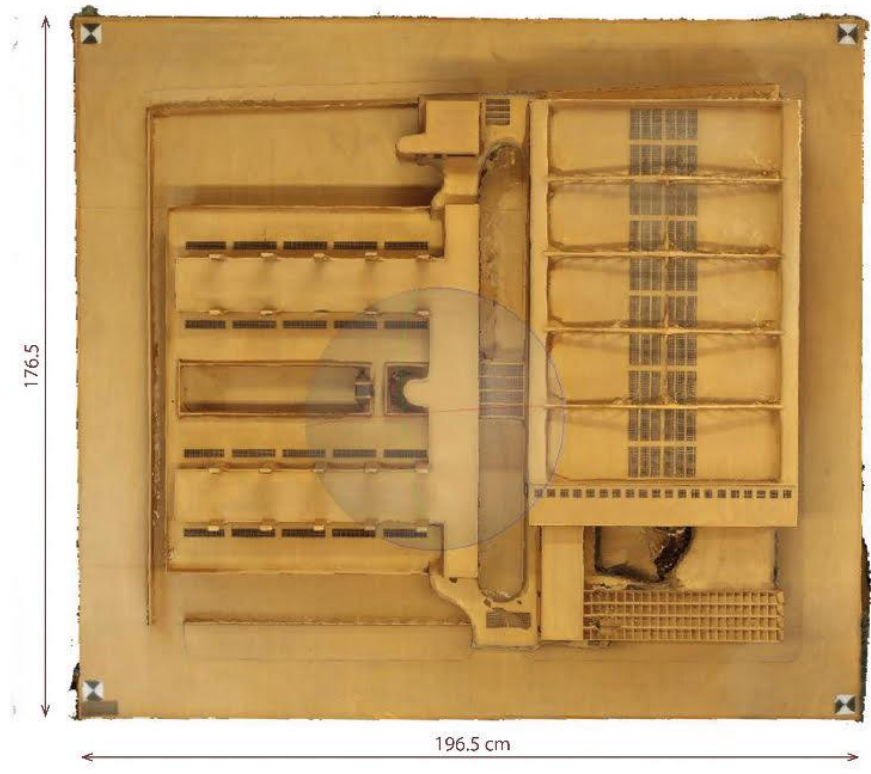

Figure 3. Orthographic image of the 3D model generated via automated SfM photogrammetry.

The object always remained at the centre of a hypothetical sphere, and the camera was always oriented towards the centre. This made the virtual reconstruction easier, especially the texturing process.

Designing the surveying plan for the data acquisition required the identification of site conditions and constraints in order to determine the optimal locations for the camera and lights.

The onsite survey conditions for the model of Turin Horse Racing were quite ideal. The maquette was totally accessible from all sides and quite accessible from the top. The camera could be positioned at a sufficient hight to capture the entire maquette, with the exception of the zenithal point of view.

We used four adjustable tripods with four $4000 \mathrm{~K}$ lights, two of them paired with reflecting umbrellas and the other two located in soft boxes to spread the light and make it uniform. The model was also equipped with markers positioned near the perimeter (to make the orientation phases and the positioning of the picture easier).

In the followed scheme, converging shots were taken all around the model at three different heights and different camera angles. The creation of deep shadows, which could cause difficulties in the collimation, orientation and design phases, was avoided. Figure 5 shows a graph of image residual values,

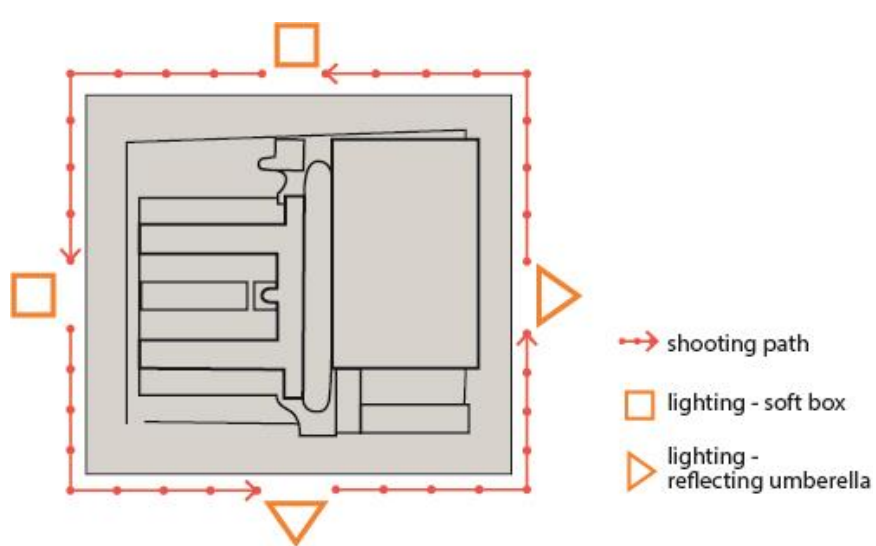

Figure 4. Schematic shooting plan. 


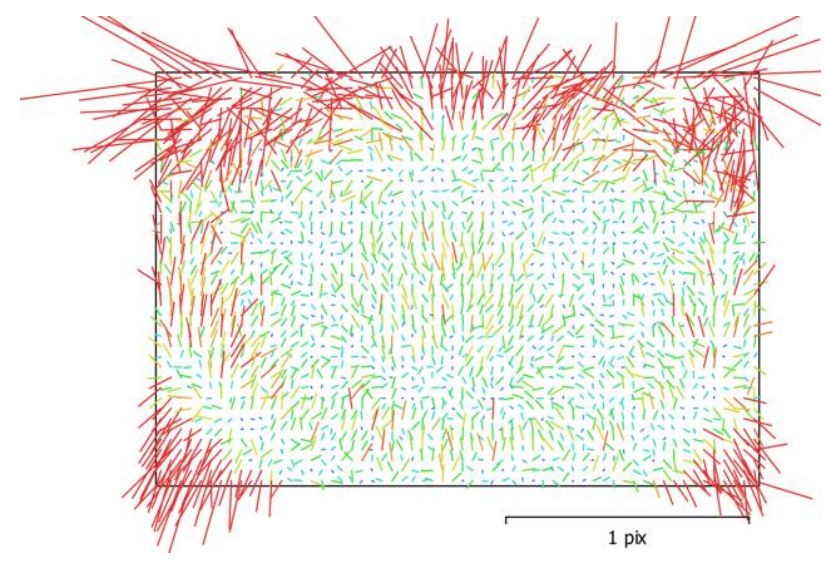

Figure 5. Image residuals for Canon EOS 1300D (18 mm).

representing the average vectors of the reprojection error for the pixels in the corresponding cells. Averaging was done across all the images in the calibration group and all the pixels inside the cell. Higher values are marked in red and lower ones in cyan.

During the survey, some measurements were taken to scale the wooden model. The scale transformation was then validated using other measurements.

The photos were taken from three different heights, so we obtained three ground sample distance (GSD) values and determined their median value (Table 1). The camera distance is also expressed as a median value because the wooden model is three-dimensional and the shooting was done by moving around it.

Although the acquisition protocols can be used for any kind of digital camera, image resolution obviously affects the quality of the final restitution. We chose to use a Canon 1300D with an 18-55 mm lens and an $18 \mathrm{mp}, 5184 X 3456$ pixel APS-C (1.6x) sensor. We manually took 390 photos in the JPG format using an $18 \mathrm{~mm}$ focal length. This choice was based on the dimensions of the surveyed object, which were quite large compared to the size of the room, and the space available for walking around the model with the tripod. The tripod was always placed along the perimeter of the model. The exposure parameters, such as aperture, shutter speed and ISO settings, were set so as to achieve the highest image quality and sharpness. Considering the good lighting conditions, we fixed the ISO parameter at the value of 100 in order to prevent any type of image noise. The aperture setting was fixed at $\mathrm{f} / 8$ in order to have a wide focus and facilitate image matching. Since these two parameters were fixed, we chose to vary the shutter speed. The use of the tripod made it possible to use long exposure times without affecting the image quality.

After our fieldwork, which lasted just a few hours, we processed the data using the Metashape ${ }^{\circledR}$ environment. We then analysed the sharpness and focus quality of the images using the Estimate Image Quality function before aligning the frames using Align Photos.

Table 1. Calculation of ground sample distance.

\begin{tabular}{cccc}
\hline $\begin{array}{c}\text { Set of } \\
\text { photos }\end{array}$ & $\begin{array}{c}\text { Number of } \\
\text { aligned photos }\end{array}$ & $\begin{array}{c}\text { Camera distance } \\
\text { in } \mathrm{m}\end{array}$ & $\begin{array}{c}\text { GSD in } \\
\mathrm{mm} / \text { pixel }\end{array}$ \\
\hline Set 1 & 208 & 1.6 & 0.38 \\
Set 2 & 92 & 1.2 & 0.30 \\
Set 3 & 90 & 1.1 & 0.27 \\
Median value & & & 0.32 \\
\hline
\end{tabular}

\section{FROM PHYSICAL TO AUTOMATED MESH MODELS}

A good combination of multiple scan positions (Figure 6) made it possible to create a complete and realistic point cloud of the detected object. The workflow was completely automatic both in regard to the orientation of the images and the generation and reconstruction of the model. This condition led to an optimisation of processing times, ensuring good performance of the machine/software complex [15].

Once the photos were uploaded to Metashape ${ }^{\circledR}$, the following steps were taken taken (see also Table 2):

1. Photo alignment. This is the most important phase of the entire photogrammetric process. In this phase, the software aligns the photographs with each other, calculating their position in space and reconstructing the so-called gripping geometry. Accuracy is one of the parameters that control the photo alignment procedure. Higher accuracy settings generate more accurate camera position estimates and ensure that the software will work with the original photo size.

Considering the research purpose of this case study and the very sharp pictures that were taken, the highest accuracy setting was selected, despite the additional time this required.

Next, through a process of geometric triangulation, the software calculated the position of the elements present in the photographs in space. The quality of this alignment determines the quality of the final 3D model.

The result of this phase was a sparse point cloud (Figure 7).

2. Processing time optimisation. Before generating the dense cloud, it was necessary to clean the sparse cloud of points defined as 'disturbing' and choose depth filtering values based on the parameters of average quality and moderate depth. The Depth Filtering mode makes it possible to work on abnormal values caused by noise and blurred images. Dot groups are filtered and deleted so that they no longer appear on the final model. Metashape ${ }^{\circledR}$ implements different algorithms for different situations: the filtering is aggressive if the detection area does not contain small significant details and mild if there are small details that are important for the reconstructed scene. Moderate filtering generates an intermediate result between the previous two, or the filtering can be disabled, which is not recommended because the resulting cloud may be too noisy. For the present case study, mild filtering was selected based on the large quantity of images, so that the processing times would be reasonable and the files could be handled in other programs and used for other purposes. The mild algorithm is also particularly suitable if there are small details in the model that are important to retain during the scene reconstruction phases, as was true for our case. An object can be described in more or less detail depending on the distance between the points used to describe it. The denser a cloud is, the

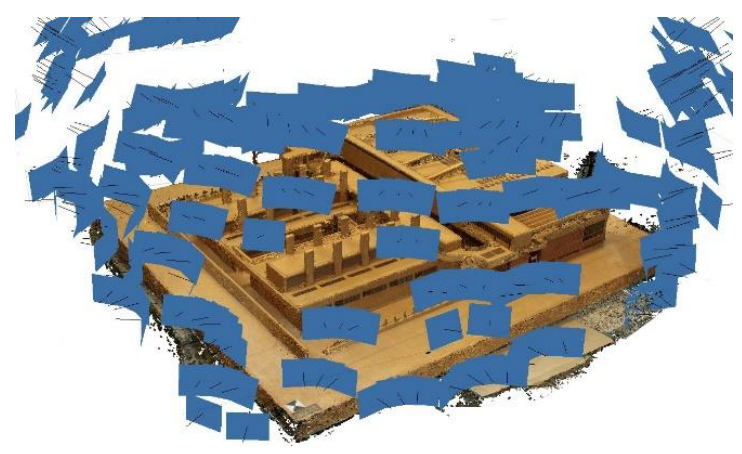

Figure 6. Photogrammetric survey: multiple image acquisition. 


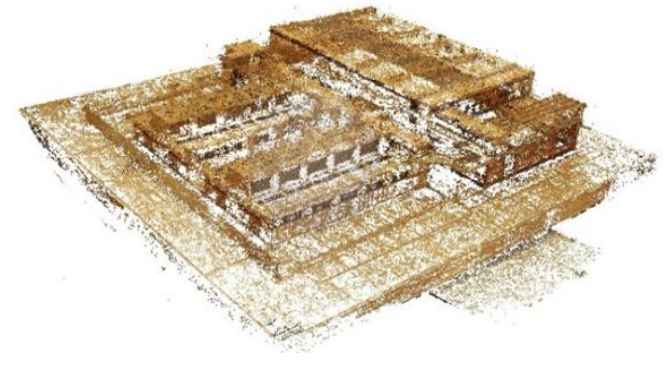

Figure 7. The sparse cloud model.

more it is able to represent the shape of the object, the surface or the detected space in a manner that is faithful to reality.

3. Building the dense cloud. In this phase, a dense cloud was constructed using dense image matching algorithms. Metashape ${ }^{\circledR}$ made it possible to generate and display a dense point cloud model (Figure 8) whose quality was set to assess the detail and geometric accuracy resulting from the reconstruction. In this case, the work was performed using a medium quality reconstruction setting. Although the images were not used with their original resolution, the result was satisfactory, considering the reasonable processing times and the easily manageable .ply file that was obtained.

4. Mesh extraction. Once the dense point cloud had been constructed, it was possible to create the mesh by connecting the points in the cloud into triangles that represent surfaces. The extraction was based on the construction of region-by-region correspondences according to the subdivision of the geometry. A polygonal model based on the newly created dense cloud was generated (Figure 9).

5. Building texture. This process improved the definition of the $3 \mathrm{D}$ representation of the work under investigation. Textures that had been obtained from the acquired images were applied to the meshes, generating a texturised model (Figure 10). A texture size value of 4096 was chosen. This value indicates the width and height of the texture in pixels and determines the number of texture files to export. Exporting textures to multiple files allows for higher texture resolution in the final model, while exporting the texture to a single file may fail due to RAM value limitations.

The generic mapping mode was chosen to create a uniform texture. The mosaic setting was chosen for the blending mode in order to pick the sharpest photos and create the most accurate result.

6. Verification of measures. The last step was the metric control and scaling of the model, that is, the correct metric dimensions were assigned to the model in order to make precise measurements on it.

While acknowledging the potential of this work and the opportunities that derive from it, it is nevertheless necessary to highlight and take into consideration its limitations. Namely, the automatic construction of the mesh model did not include the interpretation of the building's geometries and discretised its shape through an interpolated surface.

All of the operations oriented to the extraction of characteristic sections and to the generation of the model will therefore be investigated further while recognising the limitations of the approach, which inevitably presents only the external surface of the analysed object.

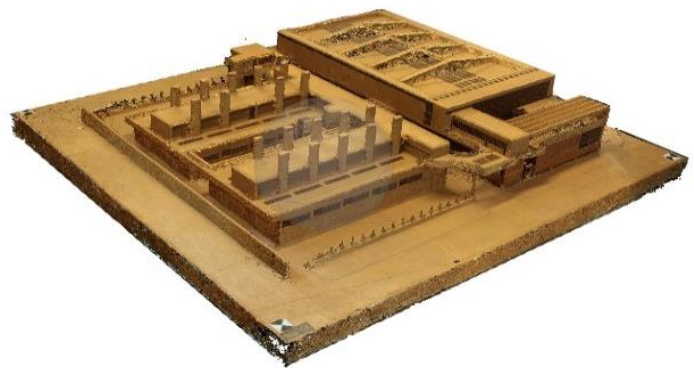

Figure 8. The dense cloud model.

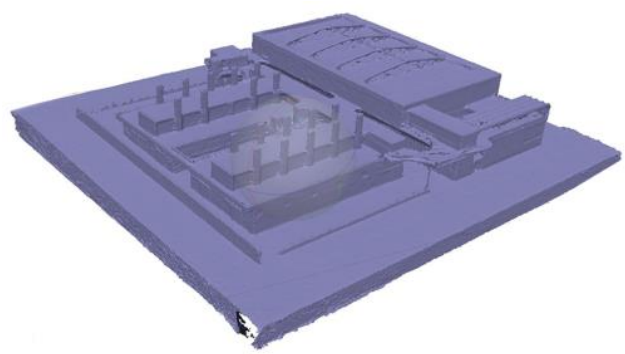

Figure 9. The mesh model.

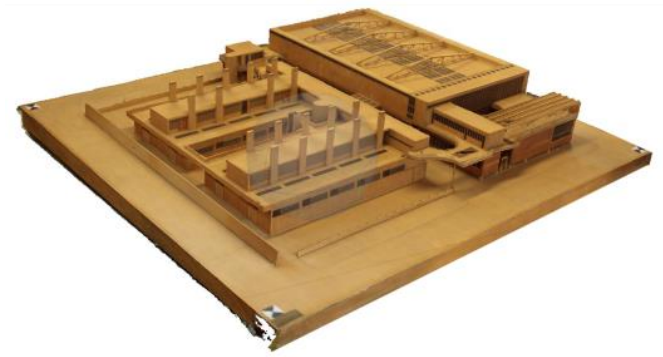

Figure 10. The texturised model.

\section{FROM POINT CLOUD TO BIM MODEL}

We decided to develop the model analysis using Revit $\mathbb{R}$ software, which allowed us to consider its geometrical characteristics and transform it into a sort of collector of associated data and information [16], [17].

Table 2. Processing parameters.

\begin{tabular}{|c|c|c|}
\hline \multicolumn{3}{|c|}{ SPARSE CLOUD } \\
\hline Points & \multicolumn{2}{|c|}{257,976} \\
\hline Alignment parameters & Accuracy & High \\
\hline Reconstruction parameters & Quality & Medium \\
\hline & Depth filtering & Mild \\
\hline \multicolumn{3}{|c|}{ DENSE CLOUD } \\
\hline Points & \multicolumn{2}{|c|}{$9,485,212$} \\
\hline Reconstruction parameters & $\begin{array}{c}\text { Quality } \\
\text { Denth filtering }\end{array}$ & Medium \\
\hline \multicolumn{3}{|c|}{ MESH } \\
\hline Faces & \multicolumn{2}{|c|}{$1,216,208$} \\
\hline Reconstruction parameters & $\begin{array}{c}\text { Quality } \\
\text { Depth filtering }\end{array}$ & $\begin{array}{l}\text { Medium } \\
\text { Mild }\end{array}$ \\
\hline \multicolumn{3}{|c|}{ GENERAL } \\
\hline Mapping mode & \multicolumn{2}{|c|}{ Generic } \\
\hline Blending mode & \multicolumn{2}{|c|}{ Mosaic } \\
\hline Texture size & \multicolumn{2}{|c|}{$4,096 \times 4,096$} \\
\hline
\end{tabular}




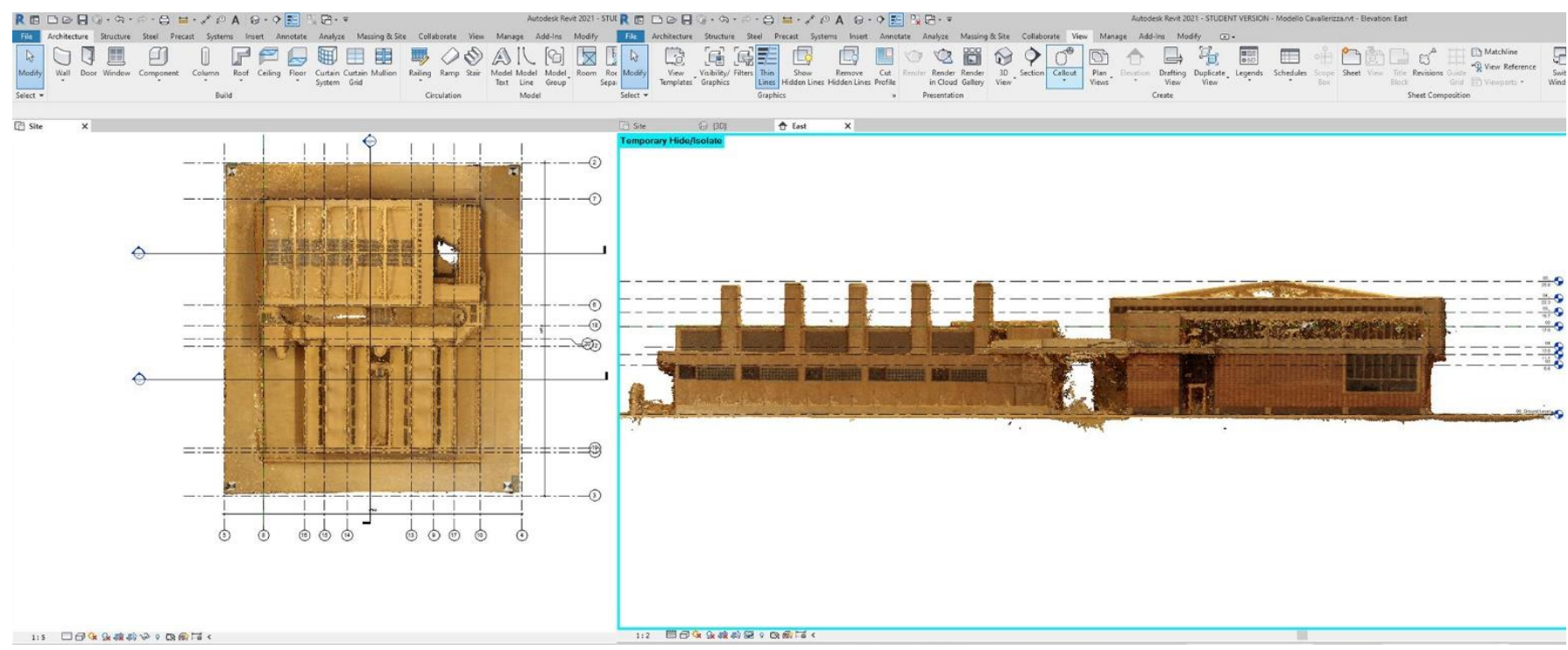

Figure 11. Autodesk Revit 2021 ${ }^{\circledR}$ : insertion of the point cloud. Site level: insertion of the grid and section; south elevation: insertion of levels.

Therefore, the point cloud was saved from Metashape ${ }^{\circledR}$ as a .pts file, imported into Recap ${ }^{\circledR}$ and saved as a .rcp file that could be opened with Revit@ (Figure 11). The formats in which the cloud was exported had to allow the transmission and the storage of information for a 3D object composed of points arranged in space with specific geometric coordinates and also needed to tie these points to RGB colorimetric information.

After importing the point cloud, we identified the best and most useful work plans (Figure 11) for the construction of the BIM model from the acquired 3D model: six vertical plane sections (four elevations, a longitudinal and a cross section) and horizontal plans, all drawn using the planes parallel to the default views.

Then we constructed the grid (Figure 11) by intercepting, thanks to Revit ${ }^{\circledR}$ object snaps, the most significant points of the point cloud. These axes are a useful trace for the construction of all the elements that will compose the model during the subsequent phases of the work.
Next, we identified the main elements of the wooden model (e.g. walls, floors, ceilings, curtain wall), including everything that was necessary for the construction of the model. In particular, the main volumes were identified.

Once the main axes and levels were defined, the geometries were modelled. Modelling with the In-Place Mass command makes it possible to create families whose elements (e.g. edges, vertices, surfaces and volumes) can be modified in space without particular constraints.

We decided to work on each level of the building and trace the point cloud with a closed outline. Once all of the various silhouettes were constructed, we created conceptual masses and local families through the extrusion of previously drawn sections (Figure 12).

This procedure was applied to all the main portions of the wooden model in order to define a single volume for each of them.

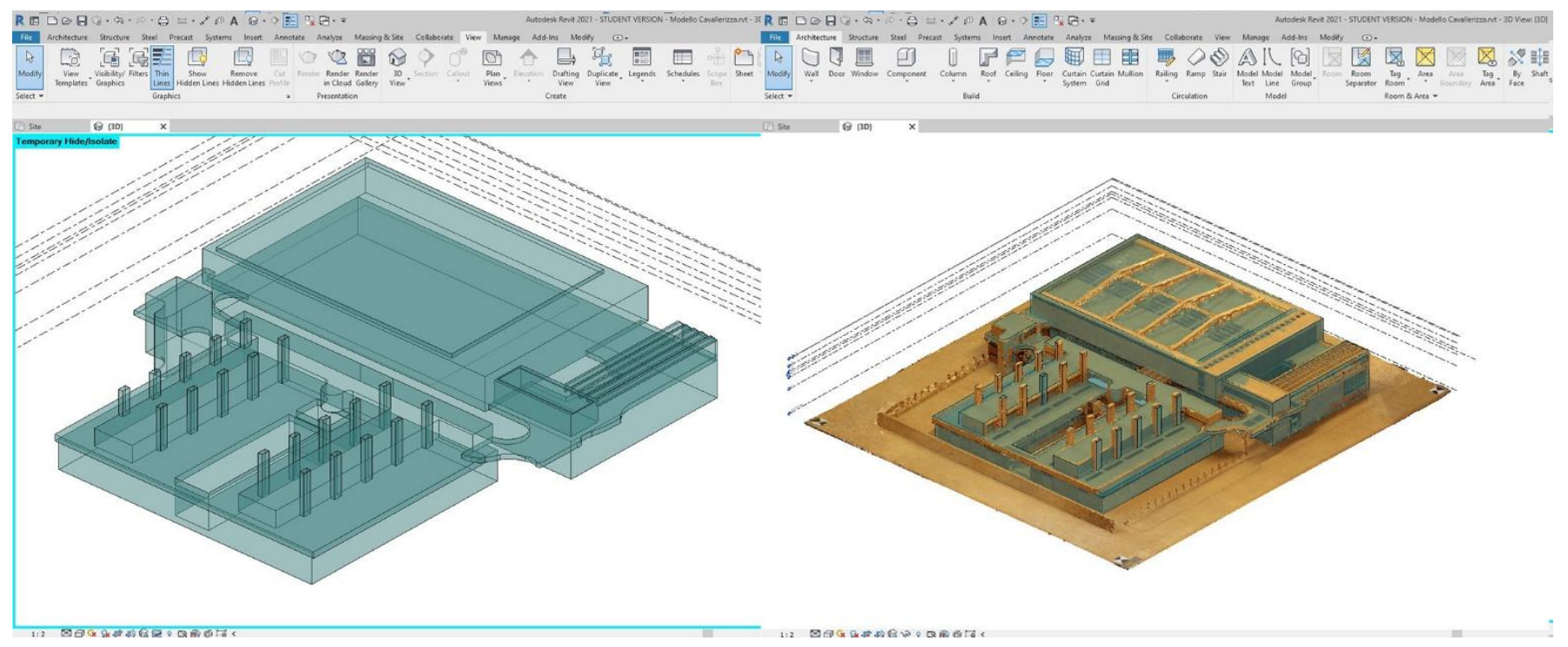

Figure 12. Autodesk Revit 2021 ${ }^{\circledR}$. 3D view: overlapping conceptual masses and point cloud; 3D view: conceptual masses of the wooden model overlapping archival drawings, conceptual masses and point cloud. 
These objects, made up of shapes, surfaces and volumes, will be the guide for the subsequent, more detailed phases of the model elaboration.

In the case of archive projects like the Turin Horse Racing maquette, it may be useful to think of the BIM model as an information collector. A BIM model creates database fields into which information can be inserted, and other fields can be added if necessary, such as, in this case, the one related to the archive drawings as well as fields for the geometry (masses) and survey data (point cloud), see Figure 12.

\section{INTERPRETATION, SHARING AND COMMUNICATION USING GEOMETRIC AND BIM MODELS AND AUGMENTED REALITY EXPERIENCES}

In the present case study, the wooden model is one of the first, if not the first, interpretative representations of the Turin Horse Racing.

As far as we learned from the heirs of the company that built the wooden model (Falco \& Boulanger s.a.s., Moro Esculapio), it was likely made between the 1970s and 1980s, i.e. after the demolition of the building. We can therefore imagine that the model was constructed from the same iconographic material that guided the creation of the digital 3D model.

Mollino's Turin Horse Racing was immediately recognised as a masterpiece by contemporary critics: in the early 1940s Giuseppe Pagano, Armando Melis and Gio Ponti featured the building in the most famous journals of the time [18]-[20].

Therefore, the documentary iconographic materials range from the original sketches, diagrams, technical drawings and perspective views to the drawings prepared by Mollino for publishing and the photographs and photomontage taken after construction and prepared by Mollino and Riccardo Moncalvo (Figure 13-Figure 16). A BIM model could be effectively used to collect a selection of these materials along with the journal articles and the texturised model obtained through SfM survey. Moreover, a BIM model created from the most reliable and consistent original drawings would document a design phase that could be interesting to compare with the mesh model obtained by photo modelling. Another possible application could be a process of reverse engineering from the point cloud acquisition of the wooden model to BIM modelling with the aim of determining the design phase expressed in the wooden model and comparing this with the digital model realised from design drawings.

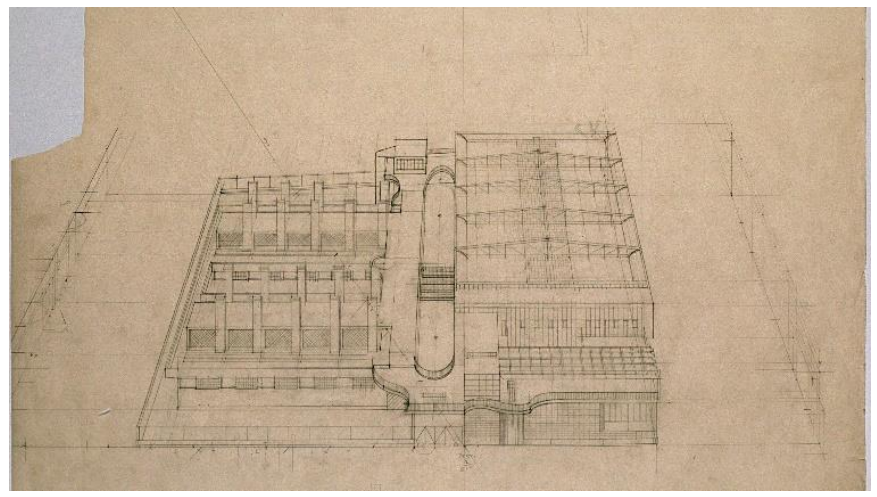

Figure 13. Mollino, technical ink perspective drawing of Turin Horse Racing (Archivi BCA, Politecnico di Torino. Fondo Carlo Mollino).

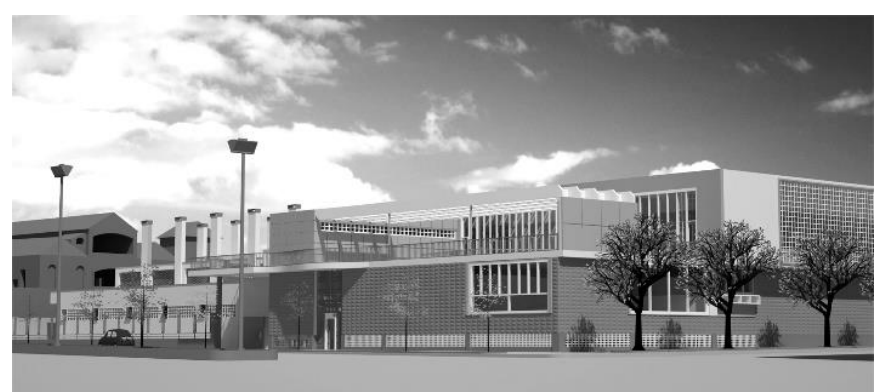

Figure 14. Reconstructive digital model of Turin Horse Racing in the urban context of the time (Modelling: Florida Canaj).

The final step of this experience broadens the scope of augmented reality (AR) applications from the archival design drawings to the wooden maquette.

This process applies the results of previous experiences [22][24] involving the recognition and tracking of two and threedimensional objects in AR applications to the collected data. Recent developments in this field relate to the technology available on widespread mobile devices (e.g. tablets and smartphones) that enable real-time 3D scanning. Software development kits like Vuforia, Wikitude and ARKit feature realtime 3D object recognition and marker-less tracking. Furthermore, they are supported by many app programming environments, including Unity, which is one of the most advanced and widespread cross-platform game engines.

\section{CONCLUSIONS}

The ability to digitise a wooden model, display it in a real context and compare it with other designs highlights the potential of new digital tools and invites a new approach to the history of architecture and the treatment of cultural heritage objects. By creating an array of reproductions and representations, we can assign an important and objective/metric role to the wooden model as a part of the design process. Due to its experimental nature, this project is susceptible to changes and improvements in the various phases (from the survey through the outputs until musealisation).

In the survey phase of photogrammetry, it could be interesting to use an endoscopic camera or a compact camera

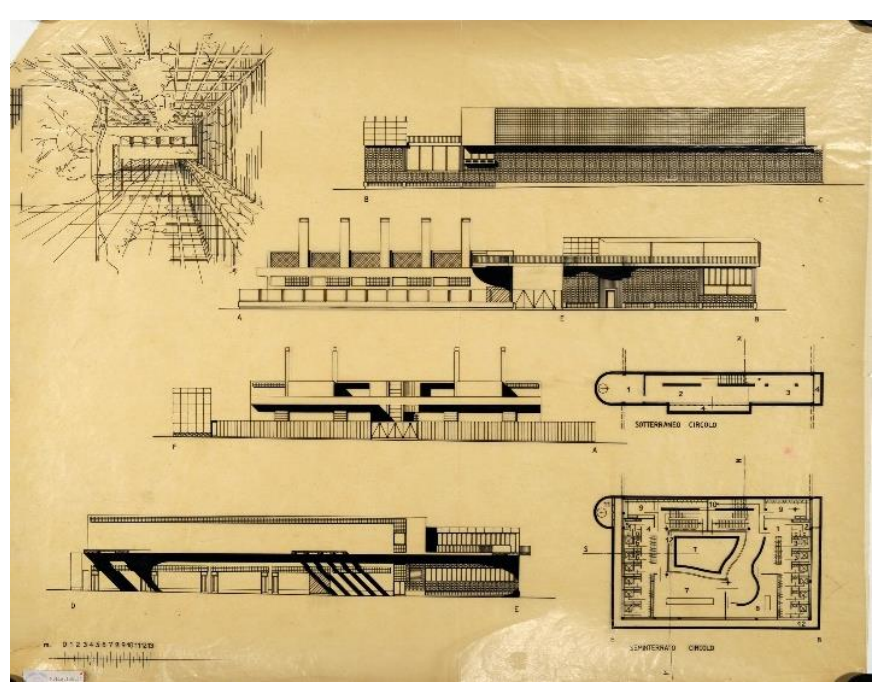

Figure 15. Mollino, technical ink drawings of Turin Horse Racing (Archivi BCA, Politecnico di Torino. Fondo Carlo Mollino). 


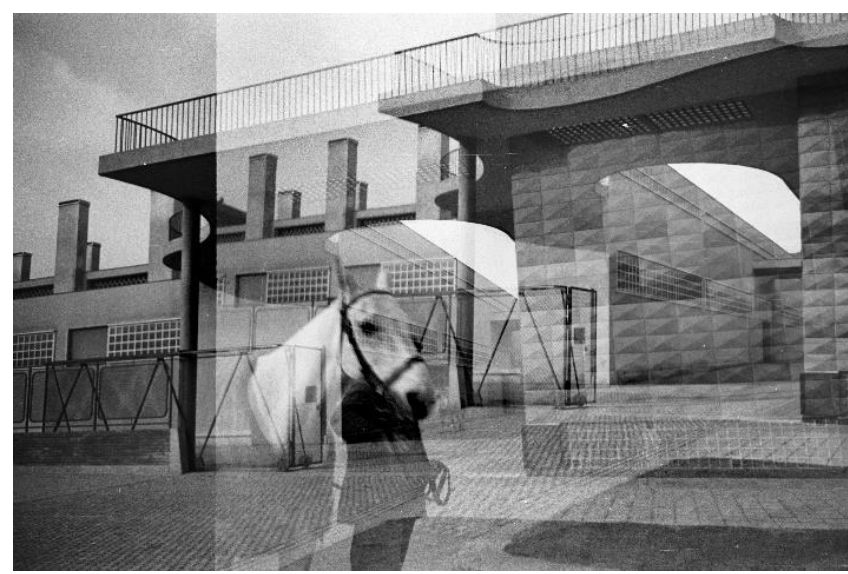

Figure 16. Mollino and Moncalvo, photomontage of Turin Horse Racing (Archivi BCA, Politecnico di Torino. Fondo Carlo Mollino).

(smaller than a reflex) to take pictures of difficult-to-access areas such as courtyards.

In the processing phase, considering the nature of point clouds as unstructured entities lacking topology or semantic discretisation and, in contrast, the nature of BIM, which requires 'smart' relationships among components, some progress could be made to ensure that the derived parametric geometry better fits the surveyed reality-based geometry.

Dedicated plug-ins, such as GreenSpider for Revit [24], could be a good choice for the translation of points into native reference snaps, which would make it possible to model elements with much more precision than can be achieved by tracing.

The output phase is probably the richest one: the use of different techniques of representation and the overlapping of different documents (e.g. historical photos, photos of the maquette and original drawings) could be very interesting (Figure 15).

This 'mixed technique' envisages a relationship between the virtual reality of the model reconstruction and the physical reality of the material of the studied object.

These interconnections between different realities can lead to greater insights and more precise analyses.

The application of digital technologies to a cultural heritage object allowed us, in this case, to obtain digital copies of a wooden model that can be published in a virtual museum and can also provide scholars with free access to an object that is difficult to handle and to move.

This experience pre-figures new virtual links between archival materials and digital interpretations, in which the archive could become a place of convergence between the real and the virtual.

Although BIM was developed for new buildings, we've seen that the typical BIM approach, which involves the gathering of data about components within semantic relationships, can be successfully applied to the modelling of historical architecture. BIM is the perfect tool for the creation of virtual and interactive archives linked to digital models, and it represents an intelligent and useful tool for the digital collection and preservation of archival documents.

The envisaged integrated and digitised archives provide a space in which drawings, documents and real and digital models can be made available to different categories of users and adapted to their different needs.

The presented case is an experimental first step of a more complex study that aims to create a sort of digital model museum in which to insert all of the historical information that is useful for telling the story of the evolution of the artefact over time, providing users with live interactive and immersive experiences of virtual and augmented reality through their personal devices.

This paper is the result of a research project carried out by the authors. Roberta Spallone wrote Sections 2 and 7. Giulia Bertola wrote Sections 5 and 6. Francesca Ronco wrote Sections 3 and 4. The Introduction and Conclusions were written by Roberta Spallone, Giulia Bertola and Francesca Ronco.

\section{REFERENCES}

[1] A. Aleardi, Un futuro per gli archivi di architettura, in: Verso un Archivio Digitale dell'opera di Maestri del XX Secolo, Architettura Disegno Modello. P. Albisinni, L. De Carlo (editors). Gangemi, Roma, 2011, ISBN 9788849220988, pp. 11-18.

[2] R. Spallone, F. Paluan, Digital representation techniques to interpret, communicate, and share 20th c. architectural archives, in: Handbook of Research on Emerging Technologies for Digital Preservation and Information Modeling. A. Ippolito, M. Cigola (editors). IGI Global, Hershey PA, 2017, ISBN 9781522506805, pp. 356-383.

[3] R. Domenichini, A. Tonicello, Il Disegno di Architettura. Guida alla Descrizione, Il Poligrafo, Padova, 2004, ISBN 9788871152653 .

[4] F. Irace, The animated archive, in: Design \& Cultural Heritage, Archivio Animato/Animated Archive. F. Irace, G. Leyla Ciagà (editors). Electa, Milano, 2013, ISBN 9789610501060, pp. 10-14.

[5] F. Irace, G. Leyla Ciagà, (editors), Design \& Cultural Heritage, Archivio Animato/Animated Archive, Electa, Milano, 2013, ISBN 9789610501060.

[6] G. Leyla Ciagà, Modern heritage in the web, in: Design \& Cultural Heritage, Archivio Animato/Animated Archive. F. Irace, G. Leyla Ciagà (editors). Electa, Milano, 2013, ISBN 9789610501060, pp. 30-42.

[7] R. Spallone, Digital reconstruction of demolished architectural masterpieces, 3D modeling, and animation: the case study of Turin Horse Racing by Mollino, in: Handbook of Research on Emerging Digital Tools for Architectural Surveying, Modeling, and Representation. S. Brusaporci (editor). IGI Global, Hershey, Pennsylvania, 2015, ISBN 9781466683792, pp. 476-509.

[8] R. Spallone, F. Carota, Digital interactive Mollino, a collection of 3D models from Carlo Mollino design drawings, in: Putting Tradition into Practice: Heritage, Place and Design. G. Amoruso (editor). Springer International Publishing AG, Cham, ISBN 9783319579368, pp. 607-617.

[9] F. Guerra, P. Vernier, Surveying and comparing the Arco dei Gavi and its historical wooden maquette, Geoinformatics FCE CTU 6, (2011), pp. 338-345.

DOI: $10.14311 /$ gi.6.42

[10] A. Rossi, P. M. Cabezos Bernal, Il valore paradigmatico del Grande Plastico di Pompei, Disegnare Idee Immagini 55 (2017), pp. 62-71.

[11] A. Adami, C. Balletti, F. Guerra, From wooden maquettes to digital model: virtual reconstruction of a design path, Proceeding XXIII International Symposium CIPA, Ottowa, Canada, 28 August - 01 September 2011, pp. 12-16.

[12] M. Docci, La Basilica Vaticana non costruita: L'opera di Antonio da Sangallo, Disegnare Idee Immagini 34 (2007), pp. 24-35.

[13] L. De Luca, La Fotomodellazione Architettonica. Rilievo, Modellazione, Rappresentazione di Edifici a Partire da Fotografie, Flaccovio Dario, Palermo, 2011, ISBN 88-579-0070-3.

[14] M. Lo Turco, F. Rinaudo, P. Piumatti, M. Calvano, A. Spreafico, G. Patrucco, The digitisation of museum collection for research, management and enhancement of tangible and intangible heritage, $20183^{\text {rd }}$ Digital Heritage International Congress, 24th International Conference on Virtual System \& Multimedia, San Francisco, USA, 26 - 30 October 2018, pp. 540-543. DOI: $\underline{10.1109 / D i g i t a l H e r i t a g e .2018 .8810128}$ 
[15] F. Bianconi, M. Filippucci, S. Catalucci, Line and points: critical analysis of evolution of archaeological survey in forty years of experiences in Umbria, DisegnareCon 10(19) (2017), pp. 18285961.

[16] V. Barrile, A. Fotia, G. Candela, E. Bernardo, Geomatics techniques for cultural heritage dissemination in augmented reality: Bronzi di Riace case study, Heritage 2 (2019), pp. 2243 2254.

DOI: $10.3390 /$ heritage2030136

[17] F. Bianconi, M. Filippucci, G. Amoruso, M. Bertinelli, From the integrated survey of historic settlements to the pattern book within the BIM, International Archives of the Photogrammetry, Remote Sensing and Spatial Information Sciences, XLII-2/W9 (2019), pp. 87-92.

DOI: $10.5194 /$ isprs-archives-XLII-2-W9-135-2019

[18] G. Moglia, F. M Ugliotti, A. Osello, M. Dellosta, BIM, virtual and augmented reality for citizen involvement in the evaluation of the urban transformation, UID 2016, $38^{\circ}$ Convegno Internazionale dei Docenti delle Discipline della Rappresentazione, Florence, Italy, 15 - 17 September 2016, pp. 1197-1200.

[19] G. Pagano, La nuova sede della Società ippica torinese, Costruzioni-Casabella 157 (1941), pp. 14-17.

[20] A. Melis, La sede della Società ippica a Torino, L'Architettura Italiana XXXVI(2) (1941), pp. 45-62.
[21] G. Ponti, Il vetro e l'architettura dello sport, in Stile, Maggiogiugno, 1941

[22] V. Palma, M. Lo Turco, R. Spallone, M. Vitali, Augmented iconography: AR applications to the fortified Turin in the Theatrum Sabaudiae, in: Defensive Architecture of the Mediterranean Vol. IX. A. Marotta, R. Spallone (editors). Politecnico di Torino, Torino, 2018, ISBN 9788885745124, pp. 1053-1060

[23] V. Palma, R. Spallone, M. Vitali, Digital interactive baroque atria in Turin: a project aimed to sharing and enhancing cultural heritage, in: EARTH 2018. A. Luigini (editor). Springer Nature, Cham, 2019, ISBN 9783030122393, pp. 314-325.

[24] V. Palma, R. Spallone, M. Vitali, Augmented Turin baroque atria: AR experiences for enhancing cultural heritage, International Archives of the Photogrammetry, Remote Sensing and Spatial Information Sciences XLII/W9 (2019), pp. 557-564 DOI: 10.5194 /isprs-archives-XLII-2-W9-557-2019

[25] S. Garagnani, A. M. Manferdini, Parametric accuracy: building information modeling process applied to the cultural heritage preservation, International Archives of the Photogrammetry, Remote Sensing and Spatial Information Sciences XL 5/W1 (2013), pp. 87-92.

DOI: 10.5194/isprsarchives-XL-5-W1-87-2013 